\title{
A better effect of cilostazol for reducing in-stent restenosis after femoropopliteal artery stent placement in comparison with ticlopidine
}

This article was published in the following Dove Press journal:

Medical Devices: Evidence and Research

23 June 2011

Number of times this article has been viewed

\author{
Ichiro Ikushima' \\ Kazuchika Yonenaga' \\ Hironao Iwakiri² \\ Hideki Nagoshi ${ }^{2}$ \\ Haruhito Kumagai ${ }^{2}$ \\ Yasuyuki Yamashita ${ }^{3}$ \\ 'Department of Radiology, \\ ${ }^{2}$ Department of Cardiology, \\ Miyakonojo Medical Association \\ Hospital, Miyakonojo, Japan; \\ ${ }^{3}$ Department of Diagnostic Radiology, \\ Faculty of Life Sciences, Kumamoto \\ University, Kumamoto, Japan
}

Purpose: The purpose of this study was to assess the preventive effect of cilostazol on in-stent restenosis in patients after superficial femoral artery (SFA) stent placement.

Materials and methods: Of 28 patients with peripheral arterial disease, who had successfully undergone stent implantation, 15 received cilostazol and 13 received ticlopidine. Primary patency rates were retrospectively analyzed by means of Kaplan-Meier survival curves, with differences between the two medication groups compared by log-rank test. A multivariate Cox proportional hazards model was applied to assess the effect of cilostazol versus ticlopidine on primary patency.

Results: The cilostazol group had significantly better primary patency rates than the ticlopidine group. Cumulative primary patency rates at 12 and 24 months after stent placement were, respectively, $100 \%$ and $75 \%$ in the cilostazol group versus $39 \%$ and $30 \%$ in the ticlopidine group $(P=0.0073$, log-rank test). In a multivariate Cox proportional hazards model with adjustment for potentially confounding factors, including history of diabetes, cumulative stent length, and poor runoff, patients receiving cilostazol had significantly reduced risk of restenosis (hazard ratio $5.4 ; P=0.042$ ).

Conclusion: This retrospective study showed that cilostazol significantly reduces in-stent stenosis after SFA stent placement compared with ticlopidine.

Keywords: cilostazol, ticlopidine, stent, primary patency rate, peripheral arterial disease, superficial femoral artery

\section{Introduction}

Stent implantation is one of the procedures to be utilized in the superficial femoral artery (SFA) treatment together with angioplasty and surgery. However, restenosis after stent implantation occurs in $15 \%$ to $66 \%$ of patients within the first 24 months and is a major limitation of the procedure. ${ }^{1-9}$ The incidence of acute and subacute thrombotic stent occlusion can be reduced with prolonged postprocedural medication, including aspirin combined with heparin and/or oral anticoagulants. However, late restenosis due to myointimal proliferation remains a problem, and so far there is no ideal medical treatment for preventing of intimal hyperplasia. Cilostazol is a potent antiplatelet agent and vasodilator that reduces vascular proliferation, and numerous studies have shown that cilostazol reduces restenosis after coronary stent implantation. ${ }^{10-16}$ However, a few reports ${ }^{17-20}$ have demonstrated the efficacy of cilostazol in preventing restenosis in SFA after stent implantation.

The purpose of the present study was to compare cilostazol and ticlopidine regarding the occurrence of in-stent stenosis in patients who had undergone stent implantation for SFA.
Correspondence: Ichiro Ikushima Department of Radiology, Miyakonojo Medical Association Hospital, Miyakonojo, 5822-3 Oiwadacho, Miyakonojo 885-0062, Japan

Tel +8I 986392322

Fax +81986391108

Email iku@cap.bbiq.jp 


\section{Materials and methods Patients}

We studied the clinical and imaging data of all consecutive patients who underwent femoropopliteal stent implantation at our institute from March 2001 to January 2006. The clinical criterion for performing the stent implantation was symptomatic peripheral arterial disease with severe intermittent claudication (Fontaine stage IIb), chronic critical limb ischemia (CCLI) with pain while the patient was at rest (Fontaine stage III), or CCLI with ischemic ulcers (Fontaine stage IV). During the study period, 28 patients underwent stent implantation. Technical success, defined as successful recanalization and $<30 \%$ residual stenosis on postprocedural angiography, was achieved in all the 28 patients who had undergone stent implantation. All patients received a self-expandable stainless steel stent (Easywallstent, Wallstent RP; Boston Scientific). Prognostic factors that were taken into account included age, gender, history of hypertension, hyperlipidemia, diabetes mellitus, smoking, renal insufficiency, respiratory tract disease, ischemic heart disease, stroke, complete vessel occlusion, cumulative stent length, inflow disease, and poor runoff. Inflow disease was defined as $>50 \%$ stenosis in the iliac or common femoral arteries proximal to the SFA. Poor runoff was defined as occlusion or significant stenosis of at least two crural arteries.

\section{Stent placement procedure}

After introduction of the sheath, $5000 \mathrm{U}$ of heparin was administered intravenously. Recanalization and stent implantation were performed after antegrade puncture of the ipsilateral femoral artery or contralateral femoral artery. After predilatation, a self-expandable stainless steel stent was implanted.

\section{Pre- and postprocedure care}

All patients received $100 \mathrm{mg}$ of aspirin and either $200 \mathrm{mg}$ of cilostazol or $200 \mathrm{mg}$ of ticlopidine daily, both started 3 days before stent implantation and continued until at least end of follow-up.

Follow-up of patients was performed after 1, 3, 6, 9 and 12 months, and at 4-month intervals thereafter, with an examination of clinical symptoms, physical examination of the distal pulses, and determination of ankle-brachial pressure index (ABI). If $A B I$ decreased by $>0.15$, a computed tomography angiogram (CTA) was performed as well as color Doppler sonography.

\section{Statistical analysis}

Continuous data were expressed as the mean \pm standard deviation and categorical data as counts. For the analysis of continuous data, Mann-Whitney $U$ test was used to assess differences between the two treatment groups. For categorical data, $\chi^{2}$ test was used. Primary patency rate was analyzed by Kaplan-Meier survival curves with differences between the two medication groups compared by log-rank test. Multivariate logistic regression analysis was performed to assess the relationship between cilostazol and in-stent stenosis and to adjust for potentially confounding factors. The following clinical characteristics were entered into the multivariate analysis in addition to the antiplatelet choice: presence or absence of diabetes, cumulative stent length, and poor or good runoff.

\section{Results}

Demographic and clinical characteristics of patients in the cilostazol group were not significantly different from those of patients in the ticlopidine group (Table 1). There were relatively large differences in the prevalence of diabetes and poor runoff and in cumulative stent length. In all cases, the technical success rate of stent placement was $100 \%$. The cumulative length of stents ranged from 3 to $34 \mathrm{~cm}$ (mean, $16.3 \mathrm{~cm}$ ). In three cases with occlusion of distal portion of popliteal artery, we tried additional angioplasty and achieved pulsatile flow to the foot. There were no periprocedural complications in any cases. After stent implantation, the clinical status of all cases was improved by at least +2 by the criteria of the Society of Vascular Surgery and Intermittent Society for Cardiovascular Surgery, and the AB improved from $0.51 \pm 0.25$ to $0.72 \pm 0.16$. All patients with rest pain had resolution of their symptoms after the procedure and did not require pain relief, and all patients with ulcers showed improvement. During the median follow-up period of 14 months (mean: 18.4 months; range: 3 to 63 months), 16 patients underwent CTA and 14 patients demonstrated $>50 \%$ restenosis. There were ten and four patients who developed in-stent stenosis in each ticlopidine and cilostazol group. In the 14 restenosis lesions, percutaneous transluminal angioplasty (PTA) was performed in 11 cases and bypass surgery was required in 3 cases. Patients receiving cilostazol had significantly better primary patency rates than those receiving ticlopidine (Figure 1). Cumulative primary patency rates at 12 and 24 months after stent placement were respectively $100 \%$ and $75 \%$ in the cilostazol group (Figure 2); versus 39\% and 30\% in the ticlopidine group (Figure 3; $P=0.0073$, log-rank test). 
Table I Demographic and cinical characteristics of patients with cilostazol and patients with ticlopidine

\begin{tabular}{|c|c|c|c|}
\hline Characteristic & Cilostazol $(n=15)$ & Ticlopidine $(n=13)$ & $P$ value \\
\hline Age (y): mean \pm standard deviation (range) & $75.8 \pm 7.9(52-87)$ & $76.9 \pm 5.5(66-87)$ & 0.68 \\
\hline Gender: male/female & $12 / 3$ & $1 \mathrm{I} / 2$ & 0.75 \\
\hline Hypertension: +/- & $12 / 3$ & $\mathrm{II} / 2$ & 0.75 \\
\hline Hyperlipidemia: +/- & $6 / 9$ & $5 / 8$ & 0.93 \\
\hline Diabetes mellitus: $+/-$ & $10 / 5$ & $6 / 7$ & 0.27 \\
\hline Smoking: + /- & $13 / 2$ & $12 / 1$ & 0.63 \\
\hline Renal insufficiency (serum creatinine $>2 \mathrm{mg} / \mathrm{dL}$ ) & 3 & 3 & 0.84 \\
\hline Respiratory tract disease & 4 & 2 & 0.40 \\
\hline History of ischemic heart disease: $+/-$ & $8 / 7$ & $8 / 5$ & 0.66 \\
\hline History of stroke: + /- & $6 / 9$ & $5 / 8$ & 0.93 \\
\hline \multicolumn{4}{|l|}{ Fontaine stage of peripheral artery disease } \\
\hline Ilb & 9 & 9 & \\
\hline III & 3 & 0 & \\
\hline IV & 3 & 4 & \\
\hline Complete vessel occlusion: + /- & $13 / 2$ & $12 / 1$ & 0.63 \\
\hline \multicolumn{4}{|l|}{ Indication for stent placement } \\
\hline Residual stenosis & 9 & 7 & \\
\hline Flow-limiting dissection & 6 & 6 & \\
\hline $\begin{array}{l}\text { Cumulative length of stents }(\mathrm{cm}) \text { : mean } \pm \\
\text { standard deviation (range) }\end{array}$ & $|4.| \pm 5.5(3-2 \mid)$ & $18.8 \pm 8.3(7-34)$ & 0.10 \\
\hline Inflow disease: $+/-$ & $4 / 11$ & $2 / 11$ & 0.47 \\
\hline Poor runoff: +l- & $3 / 12$ & $6 / 7$ & 0.14 \\
\hline
\end{tabular}

To assess the effects of cilostazol on primary patency rate, we applied a multivariate Cox proportional hazards model with adjustment for potentially confounding factors, including history of diabetes, cumulative stent length, and poor runoff. In this multivariate analysis, patients receiving cilostazol had significantly reduced risk of restenosis (hazard ratio $5.4 ; P=0.042)($ Table 2$)$.

\section{Discussion}

Peripheral arterial disease affects $12 \%$ to $14 \%$ of the general population and is part of a global vascular problem. Revascularization is indicated for the relief of

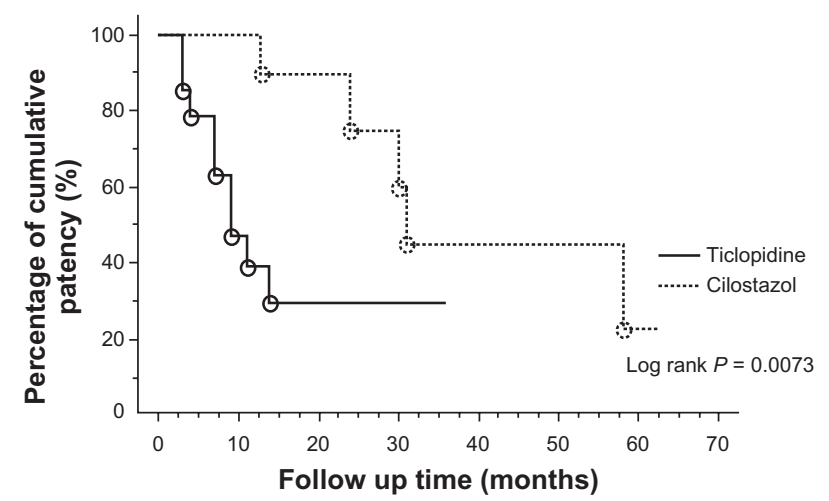

Figure I Kaplan-Meier curves of cumulative patency rates after stent implantation in the femoropopliteal artery for treatment with cilostazol versus ticlopidine. Patients receiving cilostazol had significantly higher primary patency rates than those receiving ticlopidine. ischemic symptoms. The goals of revascularization are to relieve symptom-limiting claudication or rest ischemic pain and to minimize tissue loss or limit the degree of amputation..$^{21}$ In recent years, stent implantation in SFA has been widely performed for treating patients with intermittent claudication and CCLI. This trend is partly due to substantial advances made in guidewire, balloon, and stent technology, as well as good medical therapy. The major limitation of arterial stent placement is the particularly high restenosis rate, which varies considerably (15\% to $66 \%$ at 24 months) in the published literature. ${ }^{1-9}$ Infrainguinal arterial bypass surgery (IABS) with venous grafts may remain the first choice for patients with extensive disease of the SFA. However, the BASIL trial ${ }^{22}$ indicated that in patients with CCLI due to infrainguinal atherosclerosis, the outcomes after angioplasty and IABS are generally similar for amputation-free survival, all-cause mortality, and health-related quality of life in the mid term.

Table 2 Multivariate Cox proportional hazards model used to investigate the factor to confounding the primary patency rates

\begin{tabular}{llll}
\hline & Hazard ratio & $\mathbf{9 5 \%} \mathbf{C l}$ & P value \\
\hline Cilostazol vs ticlopidine & 5.4 & I.I, 27.I & 0.042 \\
Diabetes melitus & 3.3 & $0.8,12.5$ & 0.086 \\
Cummulative length of stents & 1.1 & $0.9,1.1$ & 0.250 \\
Poor runoff & 7.5 & $1.8,29.2$ & 0.004 \\
\hline
\end{tabular}



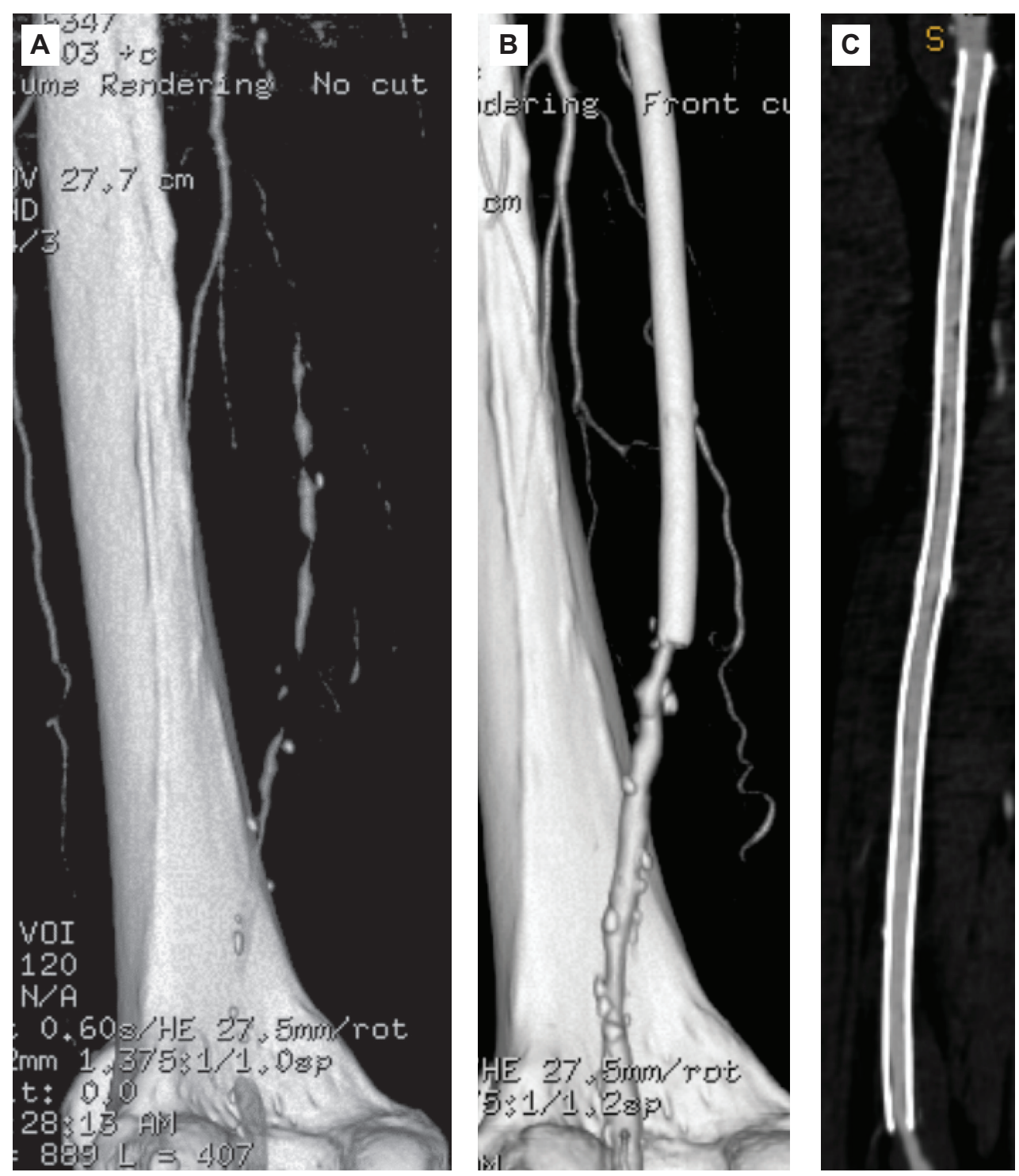

Figure 2 A 79-year-old man in the cilostazol group. (A) CT angiography (CTA) shows left superficial femoral artery (SFA) occlusion. The occlusion length of left SFA is $30 \mathrm{~cm}$. (B, C) CTA obtained 21 months after stent implantation in the left SFA, showing no restenosis.

Many factors affect the primary patency of SFA after stent implantation, including the material and length of the stent, presence of diabetes, distal runoff, and the medication used. It is widely accepted that a nitinol stent is superior to a stainless steel stent for preventing in-stent restenosis. ${ }^{6,8}$ While several randomized controlled trials failed to demonstrate any benefit of a stainless-steel stent over PTA alone, ${ }^{23-27}$ a randomized controlled single-center trial by Schillinger et $\mathrm{al}^{28}$ showed that primary implantation of a nitinol stent in the SFA was superior to PTA with optional secondary stenting. Although some reports ${ }^{4,6,29}$ have suggested that stent length, diabetes, complete vessel occlusion, and distal runoff affect primary patency, those conclusions are still controversial. There have been some reports ${ }^{30,31}$ that low-molecular-weight heparin reduces the incidence of femoropopliteal in-stent stenosis. In our present study we evaluated the intermediate-term primary patency rate after stent implantation associated with the use of cilostazol. Cumulative primary patency rates at 24 months after implantation of wallstent were $75 \%$ in the cilostazol group and $30 \%$ in the ticlopidine group. The prevalence of diabetes mellitus and poor runoff and cumulative stent length were relatively imbalanced between the cilostazol group and the ticlopidine group. We adjusted for these imbalances by using a Cox proportional hazards regression model including the factors diabetes mellitus, poor runoff, and cumulative stent length, and demonstrated that cilostazol significantly reduced mid-term in-stent restenosis, although poor runoff was a strong confounding factor. 

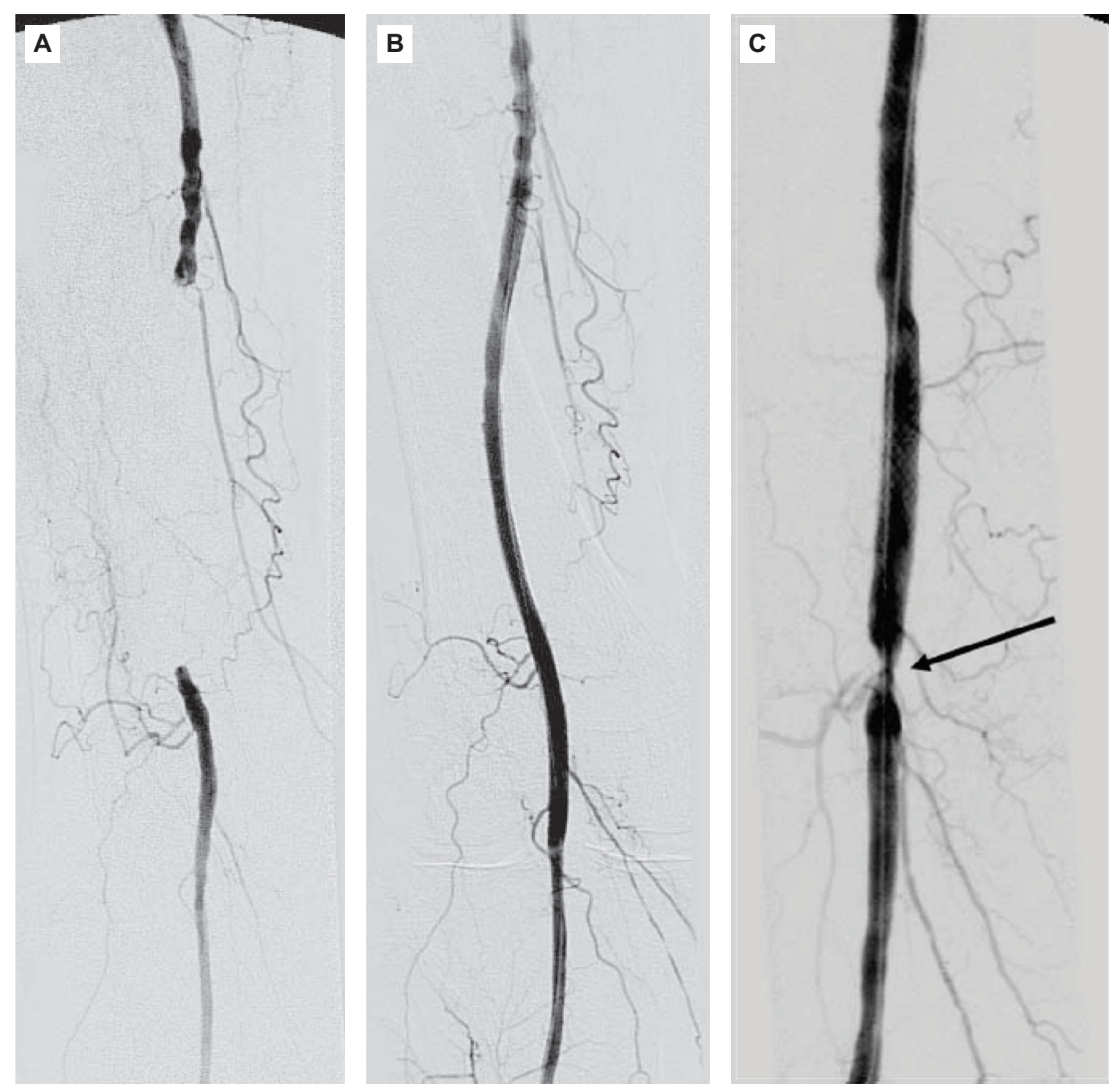

Figure 3 An 83-year-old man in the ticlopidine group. (A) Pre-procedural angiogram, showing an I I-cm occlusion of the right SFA. (B) Angiogram obtained immediately after stent implantation, showing complete patency of the vessel segment in which the stent was placed. (C) CTA obtained 5 months after stent implantation, showing restenosis (arrow). Abbreviations: CTA, computed tomography angiogram; SFA, superficial femoral artery.

Some recent reports have demonstrated the effect of cilostazol in preventing restenosis following stent replacement in the SFA. ${ }^{17-20}$ Suzuki et al ${ }^{17}$ analyzed 538 limbs after placement of a SMART stent in a study on the use of cilostazol. According to their analysis, the cilostazol group had better primary patency, at a rate of about $75 \%$ in the cilostazol group at 24 months, which was comparable with our result. Iida et al ${ }^{18}$ prospectively analyzed whether cilostazol reduces restenosis after endovascular therapy in 127 patients with femoropopliteal lesions. They used a Luminex stent in 58 patients and a Wallstent in 52 patients. The cilostazol group tended to have better primary patency in patients with either stent. Patency of Luminex stents used in the cilostazol group tended to be the highest among the group. The primary patency rates of Luminex stent and Wallstent in the cilostazol group at 24 months were both $82 \%$, which was a little higher than our result. According to previous studies and our study, cilostazol seems to prevent restenosis after stent implantation in femoropopliteal lesion.

Cilostazol is a phosphodiesterase III inhibitor with pharmacological effects that include vasodilation, inhibition of platelet activation and aggregation, inhibition of thrombosis, increased blood flow to the limbs, improvement in serum lipids with lowering of triglycerides and elevation of high density lipoprotein cholesterol, and inhibition of vascular smooth muscle cell growth. Cilostazol also has the potential to reduce of stenosis caused by proliferation of neointima. Cilostazol has been shown in multiple randomized clinical trials to decrease restenosis after coronary 
stent implantation. ${ }^{10-16}$ Cilostazol has also been shown in multiple randomized clinical trials $\mathrm{s}^{32-34}$ to decrease claudication and improve ability to walk in patients with peripheral arterial disease. Mohler et $\mathrm{al}^{35}$ evaluated the effect of cilostazol on ABI and found that cilostazol improved both resting and postexercise ABI after 24 weeks of treatment.

This study had some limitations. First, it was a preliminary study and the sample size was small. Second, it was a retrospective study. Third, we used a stainless steel stent, as that was the only metallic stent approved for use in Japan.

In conclusion, administration of cilostazol significantly improved primary patency in the SFA compared with the administration of ticlopidine. Combination of cilostazol and aspirin may be a good choice after stent implantation in femoropopliteal lesion.

\section{Disclosure}

The authors report no conflicts of interest in this work.

\section{References}

1. Cheng SW, Ting AC, Ho P. Angioplasty and primary stenting of highgrade, long-segment superficial femoral artery disease: is it worthwhile? Ann Vasc Surg. 2003;17:430-437.

2. Conroy RM, Gordon IL, Tobis JM, et al. Angioplasty and stent placement in chronic occlusion of the superficial femoral artery: technique and results. J Vasc Interv Radiol. 2000;11:1009-1020.

3. Gray BH, Olin JW. Limitations of percutaneous transluminal angioplasty with stenting for femoropopliteal arterial occlusive disease. Semin Vasc Surg. 1997;10:8-16.

4. Lugmayr HF, Holzer H, Kastner M, Riedelsberger H, Auterith A. Treatment of complex arteriosclerotic lesions with nitinol stents in the superficial femoral and popliteal arteries: a midterm follow-up. Radiology. 2002;222:37-43.

5. Martin EC, Katzen BT, Benenati JF, et al. Multicenter trial of the wallstent in the iliac and femoral arteries. J Vasc Interv Radiol. 1995; 6:843-849.

6. Sabeti S, Schillinger M, Amighi J, et al. Primary patency of femoropopliteal arteries treated with nitinol versus stainless steel selfexpanding stents: propensity score-adjusted analysis. Radiology. 2004; 232:516-521.

7. Sapoval MR, Long AL, Raynaud AC, et al. Femoropopliteal stent placement: long-term results. Radiology. 1992;184:833-839.

8. Schlager O, Dick P, Sabeti S, et al. Long-segment SFA stenting - the dark sides: in-stent restenosis, clinical deterioration, and stent fractures. J Endovasc Ther. 2005;2:676-684.

9. Vogel TR, Shindelman LE, Nackman GB, Graham AM. Efficacious use of nitinol stents in the femoral and popliteal arteries. J Vasc Surg. 2003;38:1178-1184.

10. Ge J, Han Y, Jiang H, Sun B, Chen J, Zhang S, Du Z; On behalf of the RACTS (A Randomized Prospective Antiplatelet Trial of Cilostazol Versus Ticlopidine in Patients Undergoing Coronary Stenting) Trial Investigators. RACTS: a prospective randomized antiplatelet trial of cilostazol versus ticlopidine in patients undergoing coronary stenting: long-term clinical and angiographic outcome. J Cardiovasc Pharmacol. 2005;46:162-166.

11. Kozuma K, Hara K, Yamasaki M, et al. Effects of cilostazol on late lumen loss and repeat revascularization after Palmaz-Schatz coronary stent implantation. Am Heart J. 2001;141:124-130.
12. Park SW, Lee CW, Kim HS, et al. Effects of cilostazol on angiographic restenosis after coronary stent placement. Am J Cardiol. 2000; 86:499-503.

13. Sekiya M, Funada J, Watanabe K, Miyagawa M, Akutsu H. Effects of probucol and cilostazol alone and in combination on frequency of poststenting restenosis. Am J Cardiol. 1998;82:144-147.

14. Take S, Matsutani M, Ueda H, et al. Effect of cilostazol in preventing restenosis after percutaneous transluminal coronary angioplasty. Am J Cardiol. 1997;79:1097-1099.

15. Tsuchikane E, Fukuhara A, Kobayashi T, et al. Impact of cilostazol on restenosis after percutaneous coronary balloon angioplasty. Circulation. 1999;100:21-26.

16. Zhang Z, Foster JK, Kolm P, et al. Reduced 6-month resource use and costs associated with cilostazol in patients after successful coronary stent implantation: results from the Cilostazol for RESTenosis (CREST) trial. Am Heart J. 2006;152:770-776.

17. Suzuki K, Iida O, Soga Y, et al. Long-term results of the S.M.A.R.T. Control (TM) stent for superficial femoral artery lesions, J-SMART registry. Circ J. 2011;75:939-944.

18. Iida O, Nanto S, Uematsu M, Morozumi T, Kitakaze M, Nagata S. Cilostazol reduces restenosis after endovascular therapy in patients with femoropopliteal lesions. J Vasc Surg. 2008;48:144-149.

19. Soga Y, Iida O, Hirano K, Yokoi H, Nanto S, Nobuyoshi M. Mid-term clinical outcome and predictors of vessel patency after femoropopliteal stenting with self-expandable nitinol stent. J Vasc Surg. 2010; 52:608-615.

20. Soga Y, Yokoi H, Kawasaki T, et al. Efficacy of cilostazol after endovascular therapy for femoropopliteal artery disease in patients with intermittent claudication. J Am Coll Cardiol. 2009;53:48-53.

21. Shammas NW. Epidemiology, classification, and modifiable risk factors of peripheral arterial disease. Vasc Health Risk Manag. 2007; 3:229-234.

22. Adam DJ, Beard JD, Cleveland T, et al. Bypass versus angioplasty in severe ischemia of the leg (BASIL): multicentre, randomized controlled trial. Lancet. 2005;366:1925-1934.

23. Becquemin JP, Favre JP, Marzelle J, Nemoz C, Corsin C, Leizorovicz A. Systematic versus selective stent placement after superficial femoral artery balloon angioplasty: a multicenter prospective randomized study. J Vasc Surg. 2003;37:487-494.

24. Cejna M, Thurnher S, Illiasch H, et al. PTA versus Palmaz stent placement in femoropopliteal artery obstructions: a multicenter prospective randomized study. J Vasc Interv Radiol. 2001;12:23-31.

25. Grimm J, Muller-Hulsbeck S, Jahnke T, Hilbert C, Brossmann J, Heller M. Randomized study to compare PTA alone versus PTA with Palmaz stent placement for femoropopliteal lesions. J Vasc Interv Radiol. 2001;12:935-942.

26. Vroegindeweij D, Vos LD, Tielbeek AV, Buth J, vd Bosch HC. Balloon angioplasty combined with primary stenting versus balloon angioplasty alone in femoropopliteal obstructions: a comparative randomized study. Cardiovasc Intervent Radiol. 1997;20:420-425.

27. Zdanowski Z, Albrechtsson U, Lundin A, et al. Percutaneous transluminal angioplasty with or without stenting for femoropopliteal occlusions? a randomized controlled study. Int Angiol. 1999;18:251-255.

28. Schillinger M, Sabeti S, Loewe C, et al. Balloon angioplasty versus implantation of nitinol stents in the superficial femoral artery. $N E n g l$ J Med. 2006;354:1879-1888.

29. Strecker EP, Boos IB, Gottmann D. Femoropopliteal artery stent placement: evaluation of long-term success. Radiology. 1997; 205:375-383.

30. Strecker EP, Boos IB, Gottmann D, Vetter S. Clopidogrel plus longterm aspirin after femoro-popliteal stenting. The CLAFS project: 1- and 2-year results. Eur Radiol. 2004;14:302-308.

31. Strecker EP, Gottmann D, Boos IB, Vetter S. Low-molecular-weight heparin (reviparin) reduces the incidence of femoropopliteal in-stent stenosis: preliminary results of an ongoing study. Cardiovasc Intervent Radiol. 1998;21:375-379. 
32. Beebe HG, Dawson DL, Cutler BS, et al. A new pharmacological treatment for intermittent claudication: results of a randomized, multicenter trial. Arch Intern Med. 1999;159:2041-2050.

33. Dawson DL, Cutler BS, Hiatt WR, et al. A comparison of cilostazol and pentoxifylline for treating intermittent claudication. $\mathrm{Am} \mathrm{J} \mathrm{Med}$. 2000;109:523-530.
34. Dawson DL, DeMaioribus CA, Hagino RT, et al. The effect of withdrawal of drugs treating intermittent claudication. Am J Surg. 1999; 178:141-146.

35. Mohler ER 3rd, Beebe HG, Salles-Cuhna S, et al. Effects of cilostazol on resting ankle pressures and exercise-induced ischemia in patients with intermittent claudication. Vasc Med. 2001;6:151-156.

\section{Publish your work in this journal}

Medical Devices: Evidence and Research is an international, peerreviewed, open access journal that focuses on the evidence, technology, research, and expert opinion supporting the use and application of medical devices in the diagnosis, treatment and management of clinical conditions and physiological processes. The identification of novel devices and optimal use of existing devices which will lead to improved clinical outcomes and more effective patient management and safety is a key feature. The manuscript management system is completely online and includes a quick and fair peer-review system. Visit http://www. dovepress.com/testimonials.php to read real quotes from authors.

Submit your manuscript here: http://www.dovepress.com/medical-devices-evidence-and-research-journal 